TAP CHÍ KHOA HỌC ĐẠI HỌC TÂN TRÀO
ISSN: 2354 - 1431

\title{
Xây dụng đạo đức công vụ cho cán bộ, công chức, viên chức ở Việt Nam hiện nay
}

\author{
Hà Thị Thu Trang ${ }^{a^{*}}$ \\ ${ }^{a}$ Trưòng Đại học Tân Trào \\ "Email: hathutrang.ht@gmail.com
}

\section{Thông tin bài viết}

Ngày nhận bài:

14/02/2019

Ngày duyệt đăng:

10/3/2019

\section{Tù khóa:}

Đạo đức; công vụ; đạo đức công vư; cán bộ; công chức; viên chức.

\section{Tóm tắt}

Sự suy thoái tư tưởng chính trị, đạo đức, lối sống tất yếu dẫn tới sự suy yếu của tổ chức và năng lực lãnh đạo, sức chiến đấu của Đảng. Việc ngăn chặn và đẩy lùi tình trạng suy thoái về tư tưởng chính trị, đạo đức, lối sống, trong cán bộ, công chức viên chức là nhiệm vụ hết sức quan trọng trong công tác xây dựng Đảng. Do đó, cần đẩy mạnh xây dựng đạo đức công vụ cho cán bộ, công chức, viên chức ở Việt Nam hiện nay.

\section{1. Đặt vấn đề}

Các vấn đề liên quan đến hoạt động công vụ và đạo đức công vụ của cán bộ công chức, viên chức hiện nay được quy định trong các văn bản pháp luật của nước ta: "Nhà nước được tổ chức và hoạt động theo Hiến pháp và pháp luật, quản lý xã hội bằng Hiến pháp và pháp luật, thực hiện nguyên tắc tập trung dân chủ. Các cơ quan nhà nước, cán bộ, công chức, viên chức phải tôn trọng Nhân dân, tận tụy phục vụ Nhân dân, liên hệ chặt chẽ với Nhân dân, lắng nghe ý kiến và chịu sự giám sát của Nhân dân; kiên quyết đấu tranh chống tham nhũng, lãng phí và mọi biểu hiện quan liêu, hách dịch, cửa quyền." (Điều 8 - Hiến pháp nuớc Cộng hòa xã hội chủ nghĩa Việt Nam 2013). Khi thi hành công vụ, cán bộ, công chức, viên chức phải đảm bảo các nguyên tắc: “1. Tuân thủ Hiến pháp và pháp luật. 2. Bảo vệ lợi ích của Nhà nước, quyền, lợi ích hợp pháp của tổ chức, công dân. 3. Công khai, minh bạch, đúng thẩm quyền và có sự kiểm tra, giám sát. 4 . Bảo đảm tính hệ thống, thống nhất, liên tục, thông suốt và hiệu quả. 5. Bảo đảm thứ bậc hành chính và sự phối hợp chặt chẽ." (Điều 3, Luật cán bộ, công chưc 2008). Tuy nhiên trong thực tế một bộ phận không nhỏ cán bộ, công chức, viên chức của cơ quan hành chính nhà nước chưa thực sự làm tròn trách nhiệm, nghĩa vụ trong hoạt động công vụ. Do đó cần thay đổi lề lối và phương thức làm việc của cán bộ, công chức, viên chức và lập lại kỷ cương hành chính trong hoạt động công vụ để đáp ứng yêu cầu hội nhập và phát triển của đất nước.

2. Xây dựng đạo đức công vụ cho cán bộ, công chức, viên chức ở nước ta hiện nay

\subsection{Khái niệm dạo đúc công vụ}

“Đạo đức là một hình thái ý thức xã hội đặc biệt, có tác dụng điều chỉnh hành vi của con người trên cơ sở sự đối lập thiện và ác. Hình thái ý thức xã hội này tồn tại song song cùng với những hình thái ý thức xã hội khác như pháp luật, tôn giáo, khoa học...Với tư cách là một hình thái ý thức xã hội, đặc trưng của đạo đức là ở chỗ, nó phản ánh tồn tại xã hội bằng các quy tắc, chuẩn mực về lối ứng xử giữa con người với các thành viên trong xã hội và xã hội nói chung liên quan đến lợi ích của con người, cộng đồng, xã hội." (Giáo trình Đạo đức vàphưong pháp dạy học đạo đưc ở tiểu học, trang 7) 
Đạo đức công vụ là một trong những bộ phận cấu thành của đạo đức xã hội, được quan niệm là những tiêu chuẩn đạo đức nhất định mà người cán bộ, công chức, viên chức phải tuân thủ thực hiện các hoạt động công vụ nằm trong phạm vi chức trách của mình, chi phối hành vi khi cán bộ, công chức, viên chức thực hiện hoạt động công vụ. Như vậy, đạo đức công vụ cũng là một dạng của đạo đức nghề nghiệp hiểu theo nghĩa rộng, mặc dù trong công vụ có thể gồm rất nhiều các nghề nghiệp khác nhau.

Đạo đức công vụ bao hàm trong đạo đức cách mạng và được thể hiện trong các hành vi cụ thể qua công việc của mỗi cán bộ, công chức, viên chức. Đạo đức công vụ có những quy tắc, chuẩn mực nhất định bắt buộc mỗi cán bộ, công chức, viên chức phải tuân thủ. Đạo đức công vụ của mỗi cán bộ, công chức, viên chức là yếu tố cốt lõi bảo đảm cho hoạt động quản lý nhà nước và cung cấp dịch vụ công của Nhà nước có hiệu quả. Nâng cao đạo đức công vụ là nội dung đặc biệt quan trọng để giúp người cán bộ, công chức, viên chức trở thành "công bộc" của nhân dân trong quá trình thi hành công vụ.

\subsection{Các quy định về đạo đúc công vụ ở nước ta}

Do gắn liền với hoạt động của người cán bộ, công chức, viên chức nên các giá trị công vụ thường được pháp lý hóa trong các văn bản quy phạm pháp luật. Nội dung của các chuẩn mực đạo đức công vụ được ghi nhận trong Hiến pháp đã được cụ thể hóa trong nhiều văn bản pháp luật như: Luật cán bộ, Luật phòng, chống tham nhũng, Luật thực hành tiết kiệm, chống lãng phí... và nhiều quy định của các ngành, các cấp.

Đối với Đảng, Nhà đối và nhân dân thì Cán bộ, công chức phải thực hiện nghĩa vụ: “1. Trung thành với Đảng Cộng sản Việt Nam, Nhà nước Cộng hòa xã hội chủ nghĩa Việt Nam; bảo vệ danh dự Tổ quốc và lợi ích quốc gia; 2. Tôn trọng nhân dân, tận tụy phục vụ nhân dân. 3. Liên hệ chặt chẽ với nhân dân, lắng nghe ý kiến và chịu sự giám sát của nhân dân. 4. Chấp hành nghiêm chỉnh đường lối, chủ trương, chính sách của Đảng và pháp luật của Nhà nước." (Điều 8, Luật cán bộ, công chức 2008).

Luật cán bộ công chức cũng quy định về đạo đức của cán bộ, công chức: "Cán bộ, công chức phải thực hiện cần, kiệm, liêm, chính, chí công vô tư trong hoạt động công vụ." (Điều 15, Luật cán bộ, công chúc 2008).

Trong hoạt động nghề nghiệp Viên chức phải thực nhiện nghĩa vụ: "1. Thực hiện công việc hoặc nhiệm vụ được giao bảo đảm yêu cầu về thời gian và chất lượng. 2. Phối hợp tốt với đồng nghiệp trong thực hiện công việc hoặc nhiệm vụ. 3. Chấp hành sự phân công công tác của người có thẩm quyền. 4. Thường xuyên học tập nâng cao trình độ, kỹ năng chuyên môn, nghiệp vụ. 5. Khi phục vụ nhân dân, viên chức phải tuân thủ các quy định sau: a) Có thái độ lịch sự, tôn trọng nhân dân; b) Có tinh thần hợp tác, tác phong khiêm tốn; c) Không hách dịch, cửa quyền, gây khó khăn, phiền hà đối với nhân dân; d) Chấp hành các quy định về đạo đức nghề nghiệp. 6 . Chịu trách nhiệm về việc thực hiện hoạt động nghề nghiệp. 7. Thực hiện các nghĩa vụ khác theo quy định của pháp luật." (Điều17. Luật viên chức 2010)...

Cùng với việc ban hành Luật Cán bộ, công chức và Luật Viên chức, chế định đạo đức công vụ đã có bước phát triển và hoàn thiện mới, góp phần xác lập các chuẩn mực đạo đức - pháp lý cho cán bộ, công chức, viên chức Việt Nam trong tiến trình xây dựng đội ngũ cán bộ, công chức, viên chức trong sạch, vững mạnh. Luật phòng, chống tham nhũng và Luật thực hành tiết kiệm, chống lãng phí, cũng có những quy định 129/2007/NĐ-CP quy định về văn hóa công sở trong đó chứa đựng nhiều chuẩn mực đạo đức công vụ và người cán bộ, công chức, viên chức phải tuân thủ. Căn cứ vào các quy định này, nhiều ngành đã ban hành những bộ quy tắc ứng xử riêng theo đặc thù của mình để xác định các chuẩn mực đạo đức công vụ.

\subsection{Nhũ̃ng nội dung co bản của đạo đức công vụ}

Thư nhất, "Trung với nước, hiếu với dân"

Sinh thời, Chủ tịch Hồ Chí Minh đã sử dụng khái niệm "trung, hiếu" trong tư tưởng đạo đức truyền thống dân tộc, đưa vào đó một nội dung mới: "Trung với nước, hiếu với dân”, tạo nên một cuộc cách mạng trong quan niệm về đạo đức. Người cho rằng, trung với nước phải gắn liền hiếu với dân. Vì nước là của dân, còn dân lại là chủ nhân của nước, bao nhiêu quyền hành và lực lượng đều ở nơi dân, bao nhiêu lợi ích đều vì dân, cán bộ là đầy tớ của dân chứ không phải là "quan cách mạng”. 
Trung với nước là tuyệt đối trung thành với sự nghiệp dựng nước và giữ nước, trung thành với con đường đi lên của đất nước; là suốt đời phấn đấu cho Đảng, cho cách mạng. Hiếu với dân thể hiện ở chỗ thương dân, gần dân, kính trọng dân, học tập dân, phải dựa vào dân, lấy dân làm gốc.

Do đó, đối với cán bộ, công chức, viên chức trong hoạt động công vụ phải "Trung với nước, hiếu với dân" như lời Chủ tịch Hồ Chí Minh dạy bảo.

Thư hai, ý thức tôn trọng pháp luật, tuân thủ pháp luật

Cán bộ, công chức, viên chức là thành viên của bộ máy hành chính nhà nước, là người thực thi quyền lực nhà nước. Do đó, bản thân mỗi cán bộ, công chức, viên chức phải là người tiên phong, mẫu mực trong việc tuân thủ pháp luật, không ngừng nâng cao ý thức tôn trọng pháp luật.

Thư $b a$, "cần, kiệm, liêm, chính, chí công vô tư"

Cán bộ, công chức, viên chức khi thi hành công vụ phải "cần, kiệm, liêm, chính, chí công vô tư", phải làm gương cho dân theo, để đem lại hạnh phúc cho dân. Đây được coi như một phẩm chất "Trung với nước, hiếu với dân". Bởi, "cần" là siêng năng, chăm chỉ, tự lực cánh sinh; "kiệm" là tiết kiệm về thời gian, công sức, của cải... của nước, của dân; "liêm" là tôn trọng dân, trong sạch, không tham lam của dân; "chính" là đứng đắn, thẳng thắn, chính trực, "chí công vô tư" là công bằng, bình đẳng, không tư lợi cá nhân, nêu cao chủ nghĩa tập thể ... Chỉ khi nào cán bộ, công chức, viên chức thực sự "cần, kiệm, liêm, chính, chí công vô tư" thì khi đó mới có "dân giàu, nước mạnh, dân chủ, công bằng văn minh".

Thú tư, có tinh thần phục vụ nhân dân và xã hội.

Những cán bộ, công chức, viên chức là người nắm rõ nhất các đường lối, chủ trương của Đảng, chính sách pháp luật của Nhà nước, do đó khi thi hành công vụ, họ cần có tinh thần phục vụ nhân dân và xã hội một cách nhiệt tình trách nhiệm cao nhất, khi đó đường lối chủ trương của Đảng và nhà nước mới được tuyên truyền, phổ biến, quán triệt sâu rộng, hiệu quả đến nhân dân. Từ đó giúp dân có niềm tin tuyệt đối vào Đảng và nhà nước, đóng góp công sức cho sự nghiệp xây dựng và bảo vệ tổ quốc.

Các cán bộ, công chức, viên chức phải sã̃n sàng giúp đỡ nhân dân, không có thái độ hách dịch, cửa quyền, sách nhiễu, phải có thái độ ứng xử giao tiếp văn minh lịch sự. Cán bộ, công chức, viên chức không được né tránh trách nhiệm, có bản lĩnh đấu tranh với những hành vi quan liêu, tham nhũng, tiêu cực. Cần thấy được rằng, việc phục vụ nhân dân là mục tiêu hàng đầu của công vụ, là thước đo chủ yếu cho mức độ và kết quả thực hiện công vụ.

Thứ năm, tinh thần chấp hành kỷ luật và tinh thần sáng tạo trong thi hành công vụ

Với tư cách là thành viên của cơ quan hành chính nhà nước, mỗi cán bộ, công chức, viên chức thuộc một tổ chức nhất định, họ phải tuân thủ những quy định mà tổ chức đó đề ra. Họ phải chấp hành kỷ luật mọi cách tuyệt đối để đảm bảo ổn định duy trì sự tồn tại của tổ chức. Bên cạnh đó, việc sáng tạo trong công việc chuyên môn giúp công việc của cán bộ, công chức, viên chức có thể được giải quyết nhanh chóng, hiệu quả.

Thư sáu, có ý chí cầu tiến bộ, luôn phấn đấu trong công việc để hoàn thành tốt nhiệm vụ được giao

Mỗi cán bộ, công chức, viên chức trong cơ quan hành chính nhà nước đảm nhiệm một vị trí, công việc nhất định. Để hoàn thành tốt nhiệm vụ được giao họ phải không ngừng học tập, phấn đấu rèn luyện bản thân, có ý chí cầu tiến bộ, luôn đặt ra kế hoạch, mục tiêu, và phương pháp để đạt được mục tiêu đó.

Thư bảy, tinh thần thân ái, hợp tác với đồng nghiệp trong thực hiện công việc, thực hiện phê bình và tự phê bình.

Trong mối quan hệ với các đồng nghiệp, các cán bộ, công chức, viên chức phải có tinh thần hợp tác, lắng nghe, đoàn kết với nhau để học hỏi đồng nghiệp và rút kinh nghiệm cho bản thân. Đẩy mạnh việc phê bình và tự phê bình nhằm nâng cao trình độ chuyên môn và ý thức đạo đức cho bản thân và đồng nghiệp.

\subsection{Thục trạng đạo đức công vụ hiện nay}

Trong suốt tiến trình cách mạng Việt Nam, đội ngũ cán bộ, công chức, viên chức nhà nước ở các cấp đã có bước trưởng thành và tiến bộ về nhiều mặt. Đa số cán bộ, đảng viên có phẩm chất chính trị, đạo đức lối sống, có ý thức phục vụ nhân dân, được nhân dân tin tưởng. Những giá trị cốt lõi của đạo đức công vụ trong thời đại Hồ Chí Minh đã được hình thành và ngày càng được củng cố góp phần nâng cao nhận thức công vụ của cán bộ, công chức, 
viên chức, giúp họ phấn đấu, rèn luyện và nâng cao ý thức, trách nhiệm trong thực thi công vụ, qua đó nâng cao chất lượng của hoạt động công vụ.

Tuy nhiên, trong bối cảnh chuyển đổi từ nền kinh tế kế hoạch hóa tập trung sang nền kinh tế thị trường định hướng xã hội chủ nghĩa hiện nay, đội ngũ cán bộ, công chức, viên chức của nước ta cũng nảy sinh nhiều vấn đề phức tạp. Kinh tế thị trường giải phóng sức lao động, giải phóng khả năng sáng tạo của con người, tạo cơ hội và động lực để con người phát triển, phát triển cá nhân và cống hiến cho xã hội nhưng cũng làm nảy sinh nhiều tiêu cực: quá đề cao các giá trị vật chất, có tư tưởng hưởng thụ vật chất, xem thường định hướng chính trị, vi phạm pháp luật của Nhà nước... Nghị quyết Hội nghị Trung ương 4 khóa XI về "Một số vấn đề cấp bách về xây dựng Đảng hiện nay" đã đánh giá: "Một bộ phận không nhỏ cán bộ, đảng viên, trong đó có những đảng viên giữ vị trí lãnh đạo, quản lý, kể cả một số cán bộ cao cấp, suy thoái về tư tưởng chính trị, đạo đức lối sống với những biểu hiện khác nhau về sự phai nhạt ý tưởng, sa vào chủ nghĩa cá nhân ích kỷ, cơ hội, tham nhũng, lãng phí, tùy tiện, vô nguyên tắc”. Một khía cạnh khác của đạo đức công vụ là tinh thần, thái độ phục vụ nhân dân của cán bộ, công chức, viên chức. Một số cán bộ, công chức tỏ thái độ quan liêu, hách dịch, cửa quyền, nhũng nhiễu khi giải quyết công việc; trách nhiệm xử lý công việc chưa cao, còn hiện tượng đùn đẩy, né tránh trách nhiệm. Ở một số cơ quan, đơn vị vẫn xảy ra tình trạng nội bộ mất đoàn kết, có biểu hiện bè phái, không hợp tác với nhau trong thực hiện nhiệm vụ dẫn đến hiệu quả công việc không cao. Ở các địa phương, đặc biệt là cấp cơ sở, nơi diễn ra các quan hệ phức tạp giữa công dân với Nhà nước, các biểu hiện này càng rõ nét. Năm 2018, tỉnh Thanh Hóa xử lý kỷ luật đối với 17 cán bộ, công chức có vi phạm; Đảng xử lý sai phạm của nguyên Bộ trưởng Bộ Thông tin và Truyền thông - Nguyễn Bắc Son. Năm 2017, xử lý kỉ luật với Nguyễn Xuân Anh (Ủy viên Trung ương Đảng, Bí thư Thành ủy, Chủ tịch HĐND thành phố Đà Nẵng), Đinh La Thăng (Bí thư Thành ủy TP HCM).... Thực trạng này đã và đang ảnh hưởng đến uy tín của Đảng và làm giảm niềm tin của nhân dân đối với Đảng, Nhà nước, giảm chất lượng hoạt động công vụ và năng lực cạnh tranh của nền kinh tế trong bối cảnh toàn cầu hóa và hội nhập quốc tế.
Một số hạn chế trong công tác quản lý, quy định về đạo đức công vụ của cán bộ, công chức, viên chức ở Việt Nam hiện nay:

- Tình trạng thiếu hụt những quy định pháp lý về hoạt động công vụ là điều kiện cho những hành xử công vụ một cách tùy tiện, tiêu cực, nhũng nhiễu của đội ngũ cán bộ, công chức, viên chức. Các quy định pháp luật về đạo đức công vụ hiện nay vẫn còn tản mạn ở nhiều văn bản khác nhau và chưa được quan tâm đúng mức. Do đó, cần sớm xây dựng và ban hành Luật về đạo đức công vụ trên cơ sở các quy định đã có về đạo đức công vụ đã được quy định trong Hiến pháp; Luật cán bộ, công chức; Luật phòng chống tham nhũng; Luật Thực hành tiết kiệm, chống lãng phí... để thống nhất và cụ thể hóa các quy định này.

- Văn bản quy phạm pháp luật về xử lý kỷ luật còn thiếu (như trong trường hợp đã nghỉ hưu, nghỉ việc hoặc chuyển công tác, thời hiệu xử lý kỷ luật), chưa thống nhất, áp dụng vào thực tiễn còn nhiều khoảng trống, ảnh hưởng đến hiệu quả quản lý cán bộ, công chức. Nhiều hành vi vi phạm trong hoạt động thực tiễn phải bị xử lý kỷ luật, nhưng chưa được quy định.

Chẳng hạn như quy định trong Luật Cán bộ, công chức liên quan đến kỷ luật cán bộ, công chức. Khoản 1 Điều 80 của luật và Khoản 1 Điều 6 Nghị định số 34/2011 quy định về thời hiệu xử lý kỷ luật là 24 tháng mà không quy định trường hợp ngoại lệ nên trong một số trường hợp gặp khó khăn trong xử lý; cần xem xét đến trường hợp đặc biệt để thực hiện việc xử lý kỷ luật cho hợp lý.

Khoản 4 Điều 78 của luật quy định: "Việc áp dụng các hình thức kỷ luật, thẩm quyền, trình tự, thủ tục xử lý kỷ luật cán bộ được thực hiện theo quy định của pháp luật, điều lệ của Đảng Cộng sản Việt Nam, tổ chức chính trị - xã hội và văn bản của cơ quan, tổ chức có thẩm quyền". Như vậy việc xử lý kỷ luật đối với cán bộ trong các cơ quan Đảng, đoàn thể thuộc thẩm quyền hướng dẫn của Ban Bí thư; đối với cán bộ bầu cử trong các cơ quan nhà nước thuộc thẩm quyền hướng dẫn của Ủy ban Thường vụ Quốc hội. Tuy nhiên, Ủy ban Thường vụ Quốc hội chưa ban hành văn bản quy định cụ thể việc áp dụng hình thức kỷ luật, trình tự, thủ tục xử lý kỷ luật đối với cán bộ theo quy định của Luật. 


\subsection{Một số giải pháp xây dụng đạo đức công vụ} cho cán bộ, công chức, viên chức.

Để nâng cao chất lượng đạo đức công vụ, trong thời gian tới cần áp dụng nhiều giải pháp đồng bộ với những nội dung chủ yếu sau:

Một là, tăng cường công tác giáo dục tư tưởng, bồi dưỡng phẩm chất đạo đức cán bộ, công chức, viên chức bên cạnh việc nâng cao năng lực chuyên môn, tập trung vào việc truyền bá chủ nghĩa Mác Lênin và tư tưởng Hồ Chí Minh sâu rộng cho mọi đối tượng.

Hai là, nâng cao chất lượng các quy phạm pháp luật về đạo đức công vụ, xây dựng và hoàn thiện cơ chế trách nhiệm người đứng đầu. Những quy định ban đầu về trách nhiệm của người đứng đầu cơ quan, tổ chức hiện nay đã được quy định chủ yếu tại Luật phòng, chống tham nhũng và tại Nghị định 157/2007/NĐ-CP ngày 27/20/2007, tuy nhiên cần được cụ thể hóa và điều chỉnh lại cho phù hợp với điều kiện phát sinh mới.

Ba là, đổi mới và cải cách công tác quản lý cán bộ, công chức, viên chức ở tất cả các khâu từ tuyển dụng, đào tạo, bồi dưỡng, quy hoạch, bố trí sử dụng, đánh giá và giải quyết các chính sách, chế độ cho cán bộ, công chức, viên chức theo đúng các quy định của pháp luật.

Bốn là, tăng khả năng kiểm soát đối với hoạt động công vụ của cán bộ, công chức, viên chức. Việc tăng cường kiểm soát có thể được thực hiện dưới hai hình thức chủ yếu là kiểm soát từ phía xã hội (của người dân, của các tổ chức chính trị - xã hội, các cơ quan thông tin đại chúng...) và kiểm soát ngay từ nội bộ bộ máy nhà nước (qua hoạt động của hệ thống thanh tra, kiểm tra công vụ).

Năm là, thực hiện tốt công tác thi đua, khen thưởng đối với cán bộ, công chức, viên chức; khen thưởng, động viên kịp thời gương người tốt, việc tốt trong hoạt động công vụ; đồng thời kiên quyết xử lý nghiêm minh, kịp thời và công bằng nhưng sai phạm của người có hành vi vi phạm đạo đức công vụ. Thực hiện nghiêm túc chế độ tự phê bình và phê bình trong tất cả các cơ quan nhà nước các cấp nhằm đề cao giá trị đạo đức, sự hướng thiện của con người, ngăn ngừa, hạn chế sa sút, suy thoái đạo đức.

\section{Kết luận}

Xây dựng đạo đức công vụ là hoạt động giúp xây dựng và nâng cao chất lượng đội ngũ cán bộ, công chức, viên chức, đây là một trong những nội dung cơ bản của cải cách hành chính công ở Việt Nam. Tuy nhiên, trong điều kiện hội nhập và phát triển của đất nước, tốc độ tăng trưởng kinh tế chưa cao mà nhu cầu của công dân ngày càng cao thì nền hành chính công mà chúng ta đang hướng tới xây dựng phải là một nền hành chính gọn nhẹ, đơn giản, nâng cao chất lượng cung cấp các dịch vụ công cho xã hội. Công cuộc cải cách hành chính được thực hiện hiệu quả sẽ góp phần nâng cao hiệu lực, hiệu quả hoạt động của Nhà nước; tăng khả năng phát triển kinh tế - xã hội.

\section{TÀI LIỆ THAM KHẢO}

1. Đảng cộng sản Việt Nam (2011), nghị quyết TW 4 - khóa XI: "Một số vấn đề cấp bách về xây dựng Đảng hiện nay".

2. Hồ Chí Minh toàn tập (2000): Tập 6, NXB Chính trị Quốc Gia.

3. Nguyễn Hữu Hợp (2008), Giáo trình Đạo đức và phương pháp dạy học đạo đức ở Tiểu hocc, NXB Đại học Sư phạm.

4. Quốc hội nước Cộng hòa xã hội chủ nghĩa Việt Nam (2014), Hiến pháp Nước cộng hòa xã hội chủ nghĩa Việt Nam, NXB Tư pháp.

5. Quốc hội nước Cộng hòa xã hội chủ nghĩa Việt Nam (2008), Luật cán bộ, công chưc, NXB Tư pháp.

6. Quốc hội nước Cộng hòa xã hội chủ nghĩa Việt Nam (2010), Luật Viên chưcc, NXB Tư pháp.

7. Thủ tướng Chính phủ (2007), Quyết định ban hành quy chế văn hóa công sở tại các co quan hành chính nhà nước. 
Forming public morals for current cadres, civil servants and officials in Vietnam

\section{Ha Thi Thu Trang}

\section{Article info}

Recieved:

14/02/2019

Accepted:

10/3/2019

Keywords:

Morality; public service;

public service morality;

officers

\begin{abstract}
Reforming State administration will contribute to improve the effectiveness and efficiency of the State's operation, increasing the capacity of socio-economic development. Reforming State administration includes many different contents, in which the basic content of "Building and improving the quality of officers", focusing on construction public service ethics for officers.
\end{abstract}

